\title{
Application of the NAM model to the Ali-Efenti basin
}

\author{
A. Ilias ${ }^{1}$, J. Hatzispiroglou ${ }^{2}$, E. Baltas ${ }^{2}$ \\ \& E. Anastasiadou-Partheniou ${ }^{2}$ \\ ${ }^{1}$ Land Reclamation Institute, \\ National Agricultural Research Foundation (L.R.I., N.AG.RE.F.), Greece \\ ${ }^{2}$ Department of Hydraulics, Soil Science and Agricultural Engineering, \\ School of Agriculture, AUTH, Greece
}

\begin{abstract}
This paper focuses on the simulation of single rainfall-runoff events in the Ali-Efenti basin, a subbasin of the Pinios river catchment. This region suffers from frequent floods causing problems to the downstream agricultural and urban areas. Three winter storm-events were selected for the rainfall-runoff simulations. The simulation is performed using the NAM model, a basic component of the DHI MIKE 11 package. The NAM hydrological model is a deterministic, conceptual, lumped model that consists of a set of linked mathematical statements, describing in a simplified quantitative form the behavior of the land phase of the hydrological cycle. The NAM model is based on semi-empirical equations, which describe the physical structures and procedures and as a lumped, it treats each catchment as a single unit. Two of the events were used for the calibration phase, while one was used for the verification giving results with good accuracy.

Keywords: NAM, rainfall-runoff, lumped, conceptual, flood forecasting, hydrological model, hydrological simulation.
\end{abstract}

\section{Introduction}

A number of mathematical models have been proposed by different authors to face the problem of flood forecasting (Baltas, [1]). In most of these models, combinations of linear conceptual elements are used to simplify the representation of hydrological processes. Hydrologists have always been 
interested in the effects of rainfall uncertainties on the accuracy and reliability of the estimation of catchment-scale hydrological variables (runoff peak discharge, volume, etc.). The recent advent of new technologies such as high resolution data, satellites, Geographic Information Systems and high-speed computer workstations, provides new opportunities for improved hydrologic forecasting. This led to the development of distributed models for flood forecasting (Baltas and Mimikou, [2]). In more complex approaches, models for rainfall prediction were also applied. Together with the development of more feasible strategies, they can assist the operation of human-made structures and flood warning systems. This new technology led to the development of models for flood forecasting and of more complex models incorporating cloud physics linked to mesoscale dynamical models to provide rainfall forecasts for many hours ahead (Mimikou et al., [6]). Furthermore, the lumped nature of the model, gives an intrinsic weakness to the model to represent extremely uneven spatial rainfall distributions, making it necessary to work in smaller sub-basins in such cases (Yang et al., [10]). Measurement accuracy continues to be a problem, but have not prevented self-correcting hydrological models from being developed for operational use.

In the case study presented herein an attempt is made to apply a conceptual rainfall-runoff model for flood-flow forecasting in the Ali-Efenti basin of the Pinios River in central Greece. Flood phenomena in Greece usually are caused by intense rainstorms, whereas snowmelt is not a dominant factor in flood genesis. Most intense rainstorms are produced by the passage of depressions possibly accompanied by cold fronts (and rarely by warm fronts) approaching from W, SW or NW (Mimikou and Baltas, [7]). A convectional weather type (characterised by a cold upper air mass that produces dynamic instability) is also responsible for many intense storms, especially in the summer period. The orography of the Pindos mountain range plays an important role in rainfall and runoff regimes in Greece. Thus, the mean annual rainfall exceeds $1800 \mathrm{~mm}$ in the mountainous areas of western Greece whereas in eastern regions of the country may be as low as $300 \mathrm{~mm}$. This does not mean that extreme floods are uncommon in the relatively dry eastern part of Greece. Deforestation and urbanisation play an important role to flood genesis. They are responsible for the increasing severity and destructive power of floods. Deforestation, also related to soil erosion, is a major problem in Greece. It is noted that the percentage of the areas covered by forest today is $18 \%$, while at the beginning of the nineteenth century it was more than $40 \%$. Deforestation was caused mainly from human activities such as fires, illegal land reclamation, pasturing, etc. The purpose of the study is to simulate single storm flood events in the Ali Efenti catchment. Flood-flow forecasting in this area is very important because the region suffers from frequent and hazardous flash floods, causing damage and operational problems to the downstream multipurpose reservoirs and agricultural and residential areas (Daoussi, [3]). The problems occur mainly during winter and therefore a number of winter storm-events were selected for the rainfall-runoff simulations for the Ali Efenti basin. The simulation is performed using the NAM 
model, a part of the DHI MIKE 11 package. Two events were used for the calibration phase and one for the verification giving results with good accuracy.

\section{Study area and data processing}

The basin used in this study is the Ali-Efenti basin located in the Thessaly water district with drainage area $2763 \mathrm{~km}^{2}$, as shown in Fig. 1. The Thessaly plain is an agricultural region with an area of about $4000 \mathrm{~km}^{2}$. The plain is traversed by the Pinios River whose total catchment area is $10500 \mathrm{~km}^{2}$. The Pinios River passes through the Tempi ravine located $18 \mathrm{~km}$ upstream the basin outlet. The Tempi ravine as well as other narrow passes along the river course (such as in Amygdalea, $15 \mathrm{~km}$ upstream the town of Larissa) are main reasons of the flooding in the plain. Furthermore, the river natural discharge capacity is inadequate in a large part of its length. This capacity was improved 60 years ago, after the construction of levees and other protective works, but still floods remain a big problem of the region. Other reasons favouring the flood genesis in the plain are some bridges with inadequate height that have been built across the river, the vegetation of the river bed, and the construction by the farmers of "handy" barriers in the river channel for storage of irrigation water. Last but not least is the low elevation of the drainage network as compared to the flood elevation. The topography varies from narrow gorges to wide flood plains. Its vegetation varies from grasslands to dense forest, while the climate is temperate and humid with substantial seasonal variation in temperature and rainfall. Frequent and rapid changes in weather are caused by frontal air mass activity, resulting in frequent flash floods. Snowmelt is frequently a contributing factor to winter and early spring flood runoff. Regarding the ground truth monitoring, the basin is equipped with a number of hydrometeorological recording stations, as well as, stage recording stations along with permanent installations for flow measurement at selected locations in the river reach, as shown in Fig.1. Historical storm and flood events have been recorded and archived by the Public Power Corporation (PPC), the Ministry of Agriculture and the Ministry of Environment, Physical Planning and Public Works. These consist of hourly precipitation data from raingages and the corresponding streamflow rates at the outlet of the basin. Streamflow is estimated by using the hourly water level readings and the appropriate water level-discharge rating curves calibrated at the site. The stage-discharge rating curve has been derived and is described by the following equation:

$$
\mathrm{Q}=45.893939 * \mathrm{~h}^{1.1345097}
$$

The aforementioned flood events were occurred in the autumn and early winter months, so it was determined to override the snow melting component of the runoff process and the corresponding NAM component. The model was calibrated in a lumped manner by using the entire Ali-Efenti basin. The AliEfenti catchment consists of two distinct parts, the western mountainous part and 
the southeastern flat one. A distribution of the elevation classes of the catchment is presented in Table 1.

Table 1: $\quad$ Elevation classes of the Ali-Efenti catchment.

\begin{tabular}{|c|c|}
\hline Elevation Class & Percentage (\%) \\
\hline $0-500$ & 54.52 \\
\hline $500-1000$ & 29.23 \\
\hline $1000-1500$ & 13.98 \\
\hline $1500-2000$ & 2.23 \\
\hline $2000-2500$ & 0.05 \\
\hline
\end{tabular}

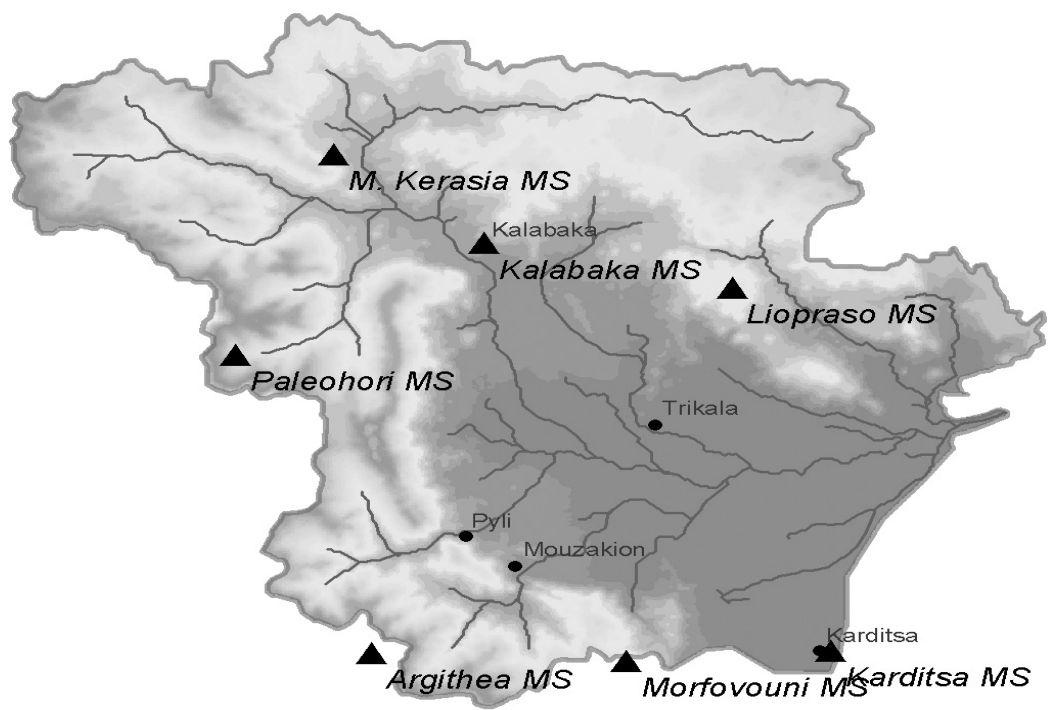

Figure 1: The Ali-Efenti catchment and the meteorological stations (MS).

The Thiessen polygon method was used in order to derive the mean meteorological values over the catchment. The other hydrological parameters, such as irrigation and groundwater abstraction are supposed to be negligible due to the period of time of the events and the small effect of these parameters when simulating single storm events.

\section{Application of the NAM model for flood-flow forecasting}

The NAM hydrological model is a deterministic, conceptual, lumped model that simulates rainfall-runoff processes at catchment scale. NAM consists of a set of 
linked mathematical statements describing in a simplified quantitative form the behavior of the land phase of the hydrological cycle. The NAM model is based on semi-empirical equations describing physical structures and procedures and it treats each catchment as a single unit. The parameters and variables represent, therefore, average values over the entire catchment. As a result, the model parameters can be evaluated from physical data of the study area, but the final parameter estimation should be performed in the calibration phase.

NAM represents the rainfall-runoff process by continuously accounting for the water content in different and mutually interrelated storages. Each storage represents the concept of different physical element of the catchment. Based on the estimated parameters and on meteorological data the model produces information about catchment's discharge, as well as, of the rest parts of the hydrological cycle, such as evapotranspiration, soil moisture in the root zone, groundwater recharge and ground water levels. The resulting catchment runoff is split conceptually into overland flow, interflow and baseflow components. The NAM model also allows modeling of human interventions in the water regime of the catchment, in terms of irrigation and groundwater pumping. In the case, where irrigation or pumping is a significant part of the water cycle, time series of irrigation and groundwater withdrawal rates are required, as mean values over the whole area of the catchment. NAM can be used for continuous hydrological modeling over a range of flows or for simulating single events and it may represent different hydrological regimes and climatic conditions (DHI, [4]).

\subsection{Model components}

The various conceptual procedures that represent the land phase of the hydrological cycle and are computed by the NAM model are:

- $\quad$ Surface storage (U). This storage represents the moisture intercepted on the vegetation, as well as water trapped in surface depressions and in the uppermost part of the ground. $\mathrm{U}_{\max }$ denotes the upper limit of the amount of water that can be retained in the surface storage. The amount of water in the surface storage is continuously diminished by evaporative consumption, as well as, by horizontal leakage (interflow). As soon as, the surface storage is fully filled, some of the excess rainfall water $\left(\mathrm{P}_{\mathrm{N}}\right)$ will enter the streams as overland flow (OF), whereas the remainder (DL) is diverted as infiltration into the lower zone (root zone) and to the ground water storage.

- Lower or root zone storage (L). The soil moisture in the root zone, a soil layer from which water can be withdrawn as evaporation and as transpiration by the plants. $\mathrm{L}_{\max }$ denotes the upper limit of the amount of water in the storage, usually considered to be the difference between Field Capacity (FC) and Permanent Wilting Point (PWP).

- Evapotranspiration $\left(\mathrm{E}_{\mathrm{p}}\right)$. Evapotranspiration demands are first met as potential evapotranspiration from the surface (U) and if the surface storage has less moisture than required $\left(\mathrm{U}<\mathrm{E}_{\mathrm{p}}\right)$, the moisture is withdrawn by root activity from the root (L) zone storage at an actual rate $\mathrm{E}_{\mathrm{a}}\left(\mathrm{E}_{\mathrm{a}} \leq \mathrm{E}_{\mathrm{p}}\right)$. This actual evapotranspiration rate $\left(\mathrm{E}_{\mathrm{a}}\right)$ is proportional to the potential 
evapotranspiration and varies linearly with the relative soil moisture content, $\mathrm{L} / \mathrm{L}_{\max }$ of the lower (root) zone:

$$
E_{a}=\left(E_{p}-U\right) \frac{L}{L_{\max }}
$$

- Overland flow. When the surface storage spills, i.e. when $U>U_{\max }$, the excess rainfall $\mathrm{P}_{\mathrm{N}}$ gives rise to overland flow, as well as, to infiltration. QOF denotes the part of $\mathrm{P}_{\mathrm{N}}$ that contributes to overland flow. It is assumed to be proportional to $\mathrm{P}_{\mathrm{N}}$ and to vary linearly with the relative soil moisture content, $\mathrm{L} / \mathrm{L}_{\max }$, of the lower (root) zone storage:

$$
Q O F=\left\{\begin{array}{cl}
C Q O F \frac{L / L_{\max }-T O F}{1-T O F} P_{N} & \text { for } L / L_{\max }>T O F \\
0 & \text { for } L / L_{\max }<T O F
\end{array}\right.
$$

where, $C Q O F$ is the overland flow runoff coefficient $(0 \leq \mathrm{CQOF} \leq 1)$, $T O F$ is the threshold value for overland flow $(0 \leq \mathrm{TOF} \leq 1)$ The proportion of the excess water $\mathrm{P}_{\mathrm{N}}$ that does not run off as overland flow infiltrates into the lower zone storage. A portion, $\Delta \mathrm{L}$, of the water available for infiltration, $\left(\mathrm{P}_{\mathrm{N}}-\mathrm{QOF}\right)$, is assumed to increase the soil moisture content $\mathrm{L}$ in the lower zone storage and the remaining amount of infiltration, $G$, is assumed to percolate deep and recharge the groundwater storage.

- Interflow. The interflow contribution, QIF, is assumed to be proportional to the amount of moisture in the upper storage, $U$, and to vary linearly with the relative moisture content of the lower zone storage:

$$
Q I F=\left\{\begin{array}{cl}
C K I F \frac{L / L_{\max }-T I F}{1-T I F} U & \text { for } L / L_{\text {max }}>T I F \\
0 & \text { for } L / L_{\text {max }}<T I F
\end{array}\right.
$$

where, CKIF is the time constant for interflow, and TIF is the root zone threshold value for interflow $(0 \leq \mathrm{TIF} \leq 1)$.

The interflow is routed through two linear reservoirs in series with the same time constant $\mathrm{CK}_{12}$ [hours]. The overland flow routing is also based on the linear reservoir concept but with variable time constant: 


$$
C K_{12}=\left\{\begin{array}{cc}
C K_{12} & \text { for } \quad O F<O F_{\text {min }} \\
C K_{12}\left(\frac{O F}{O F_{\min }}\right)^{-\beta} & \text { for } \quad O F \geq O F_{\text {min }}
\end{array}\right.
$$

where $\mathrm{OF}$ is the overland flow, $\mathrm{OF}_{\min }$ is the upper limit for linear routing $(=0.4 \mathrm{~mm} / \mathrm{hr})$ and $\beta=0.4$. The time constant for routing interflow and overland flow determines the shape of the hydrograph peaks. The value of this constant depends on the size of the catchment and how fast it responds to rainfall.

- Groundwater recharge. The amount of infiltration water, $\mathrm{G}$, recharging the groundwater storage depends on the soil moisture content of the lower (root) zone storage:

$$
G=\left\{\begin{array}{cl}
\left(P_{N}-Q O F\right) \frac{L / L_{\text {max }}-T G}{1-T G} U & \text { for } L / L_{\text {max }}>T G \\
0 & \text { for } L / L_{\text {max }} \leq T G
\end{array}\right.
$$

where, TG is the root zone threshold value for groundwater recharge $(0 \leq \mathrm{TG} \leq 1)$.

- Soil moisture content. The lower zone storage represents the water content of the root zone. The amount of the excess rainfall that remains after the apportioning of overland flow and ground water recharge water, increases the moisture content of the lower zone storage by the amount of $\Delta \mathrm{L}$ :

$$
\Delta L=P_{N}-Q O F-G
$$

- Baseflow. The baseflow component, BF, is calculated as outflow from a linear reservoir.

Modules such as, extended groundwater components, snow module, irrigation module etc. which are basic components of the model, are not directly used in this work and therefore are not described herein. Details of these modules can be found in MIKE 11 User Guide (DHI, [4])

\section{Results and discussion}

The purpose of the study is to derive a set of parameters for the NAM model to represent the catchment behavior during peak flow events, thus to produce 
realistic discharge hydrographs. The NAM model is a conceptual, lumped model, thus its parameters represent average values of some physiographic characteristics for the entire catchment. Since these parameters have a semiempirical and conceptual nature it is only possible to estimate a likely range for some of these values from knowledge of the study area. The final values of the NAM model are estimated in the calibration process based on the observed discharges (Madsen, [5]; Niel et al., [8]; Perrin et al., [9]). The available calibration objectives that are included in the calibration process of the DHINAM model are the following:

1. A good agreement between the average simulated and observed catchment runoff, in other words a good water balance.

2. A good overall agreement of the shape of the hydrograph.

3. A good agreement of the peak flows with respect to timing, rate and volume.

4. A good agreement of the low flows.

In this study the first three objectives were included in the calibration, since low flows are of no interest when estimating flood events.

The NAM model for peak flow events in Ali-Efenti catchment was calibrated using two single storm flood events (Event 1 and Event 2), as shown in Figures 2 and 3 and then verified on a third one (Event 3), as shown in Fig. 4. The most important measured characteristics of the events are given in Table 2.

Table 2: $\quad$ Storm and peak flow events under study.

\begin{tabular}{|c|c|c|c|}
\hline Parameter / Event & Event 1 & Event 2 & Event 3 \\
\hline Time period & $\begin{array}{c}26 / 10 / 1980- \\
3 / 11 / 1980\end{array}$ & $\begin{array}{c}9 / 1 / 1984- \\
16 / 1 / 1984\end{array}$ & $\begin{array}{c}21 / 12 / 1999- \\
27 / 12 / 1999\end{array}$ \\
\hline Total rain, mm & 101.2 & 77.5 & 15.9 \\
\hline Max Water Level, m & 4.64 & 5.08 & 2.23 \\
\hline Peak flow, $\mathrm{m}^{3} / \mathrm{s}$ & 261.77 & 290 & 114 \\
\hline Base flow, $\mathrm{m}^{3} / \mathrm{s}$ & 19.5 & 25.0 & 24.7 \\
\hline Total discharge, $\mathrm{Mm}^{3}$ & 60.4 & 91.6 & 30.6 \\
\hline
\end{tabular}

The behavior of the NAM model during storm events is controlled by the factors that mainly affect the discharge component that contributes highly to the peak flows, thus the overland flow component. These factors are the storage capacity of the unsaturated $\left(\mathrm{L}_{\max }\right)$ and of the surface or upper zone $\left(\mathrm{U}_{\max }\right)$, the portion of the excess rain that contributes to the overland flow (CQOF), the threshold value of saturation of the root zone storage for starting of the overland flow (TOF) and the time constant for overland flow $\left(\mathrm{CK}_{12}\right)$, which controls the shape of the hydrograph. Furthermore, the initial conditions and mostly the saturation percentage of the two storages, upper and lower, highly affect the behavior of the discharge hydrograph of a single storm event. The initial conditions required by the NAM model are also the values of the overland flow, the interflow and the baseflow at the beginning of the simulation time. 


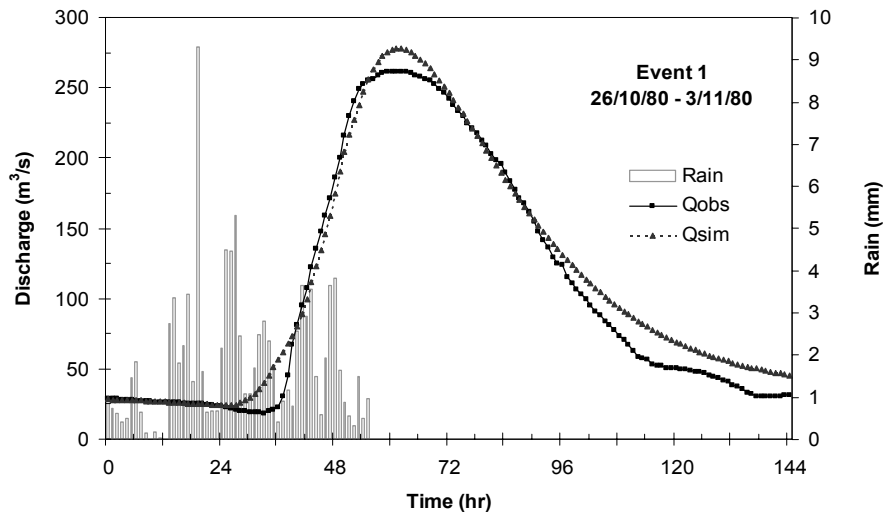

Figure 2: Observed versus computed flood hydrograph in the calibration phase.

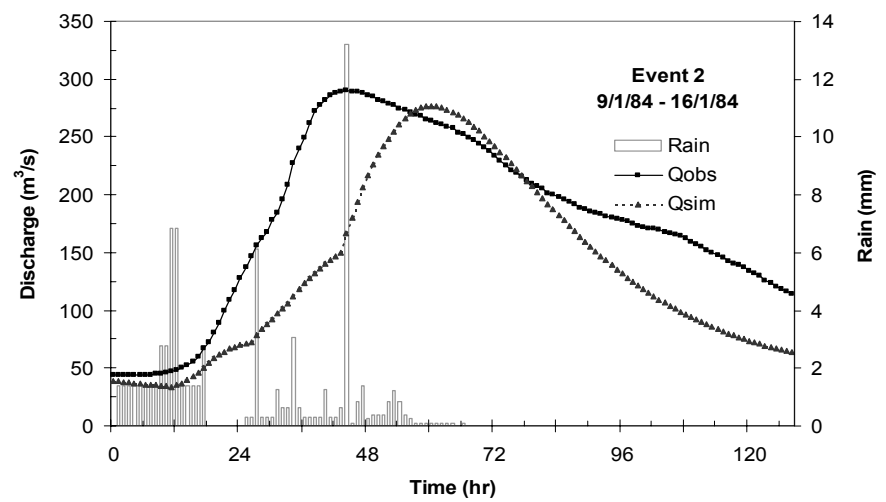

Figure 3: Observed versus computed flood hydrograph in the calibration phase.

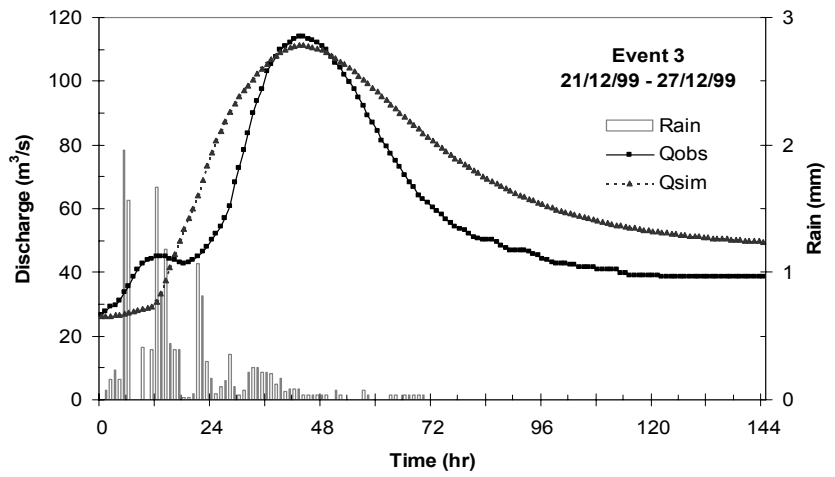

Figure 4: Observed versus computed flood hydrograph in the verification phase. 
It is noted that the combined choice of the initial value of the saturation point of the lower zone storage $\left(\mathrm{L} / \mathrm{L}_{\max }\right)$ with the threshold values for the starting point of the overland flow (TOF) virtually controls the rate with which the excess rain turns to overland flow (eq. 3). This rate becomes bigger as the saturation of the lower zone increases and gets its maximum value (CQOF) when $\mathrm{L}=\mathrm{L}_{\max }$ or $\mathrm{L} / \mathrm{L}_{\max }=1$. As a result, the knowledge of the prior water content of the catchment and the choice of the mean initial values of saturation are really critical for the derivation of the parameters set that simulates the hydrologic behavior of the catchment.

The hydrologist has to be really careful during this procedure, especially in the case of simulating single storm events. In the case of long term simulations, the choice of the initial conditions becomes less important as one may disregard the first 3 to 6 months of the NAM simulation, as it is proposed by the authors of the DHI MIKE 11 reference, in order to eliminate the influence of erroneous initial conditions.

\section{Conclusions}

The NAM rainfall-runoff model was applied in order to simulate single storm events in the Ali-Efenti catchment. The most difficult task during this process was the evaluation of the antecedent moisture condition of the basin, thus of the initial conditions of the model and especially for the saturation of the two storages, namely the lower and the upper zone $\left(\mathrm{L} / \mathrm{L}_{\max }\right.$ and $\mathrm{U} / \mathrm{U}_{\max }$ respectively). A different choice of the initial condition drives the calibration process to different results, considering the model parameters. An answer to this problem could be the prior evaluation of the model for an adequate time period (with bigger time step), while this eliminates the significance of the initial condition choice. Subsequently, the resulting model could be fine-tuned for single storm events simulation. The model was applied in two phases, (calibration and verification phase) giving good results.

\section{Acknowledgements}

This research was (in part) performed in the framework of the Project titled "Networking Perspectives of Transnational Co-operation and Participatory Planning for Integrated Water Resources Management through the promotion of new forms of Spatial Governance" of the Community Initiative INTEREG III B (2000-2006), CASDES.

\section{References}

[1] Baltas, E. A., Weather radar for real-time flood forecasting in the Pinios river basin. Proceedings of First RIPARIUS Workshop, Brussels, 27-28 October 1998.

[2] Baltas, E. A., Mimikou, M. A., Intercomparison of two models based on the spatial rainfall distribution. Hydrotechnika, Journal of the Hellenic Hydrotechnical Association, Vol. 9, December 1999. 
[3] Daoussi C., Water and environment towards one sustainable management of the water resources. The importance of the euromediterranean cooperation. Mediterranean Cooperation, Four-month review of the ISPROM, vol. 3, Cagliari, AM\&D editions, September - December 2003, pp. 45-51.

[4] DHI, "MIKE 11 User Guide - A modeling system for rivers and channels", DHI Software, 2003.

[5] Madsen, H. (DHI Water \& Environment, Agern Alle' 11, DK-2970 Hørsholm, Denmark), Automatic calibration of a conceptual rainfallrunoff model using multiple objectives. Journal of Hydrology, 235(2000), pp. 276-288.

[6] Mimikou, M. A., Baltas, E. A., and Borga, M., Improving the efficiency of the HEC1F model in flood-flow forecasting. International Journal of Modeling and Simulation, Vol.15, No:1, 1995.

[7] Mimikou, M. A., Baltas, E. A., Flood forecasting based on radar rainfall measurements. Journal of Water Resources Planning and Management, Vol. 122(1996), No: 3, pp. 151-156.

[8] Niel, H., Paturel, J.-E., and Servat, E., Study of parameter stability of a lumped hydrologic model in a context of climatic variability. Journal of Hydrology, Elsevier, 278(2003), pp. 213-230.

[9] Perrin, C., Michel, C., and Andreassian, V., Does a large number of parameters enhance model performance? Comparative assessment of common catchment model structures on 429 catchments. Journal of Hydrology, Elsevier, 242(2001), pp. 275-301.

[10] Yang, D., Herath, S., and Musiake K., Comparison of different distributed hydrological models for characterization of catchment spatial variability. Hydrological Processes, 14(2000), pp. 403-416. 